Journal of Research in Nursing

Vol. 2, No. 1, 2016

Print ISSN 2244-2723

University of Cebu

Cebu City, Cebu, Philippines

\title{
Classroom Management Needs of the Faculty of Nursing
}

\author{
Arlene L. Galon \\ Mauro Allan P. Amparado
}

\section{Abstract}

The study assessed the classroom management needs of the faculty of the College of Nursing in University of Cebu Lapu-Lapu and Mandaue, Mandaue City, Cebu, Philippines for school year 2011-2012 based on Acero's facets of classroom management (time and physical environment, classroom discipline, and routines). Further, the study described the: profile in terms of age, educational attainment, and length of teaching experience; classroom management needs; and relationship between the respondents' profile and classroom management needs. The key findings were the basis for a proposed action plan.

The descriptive-correlational design was utilized with a researcher-made tool based on Acero's facets of classroom management. Follow-up interviews were also conducted with the 22 respondents. Treatment of data include frequency, simple percentage, weighted mean, and chi-square Test of Independence.

The findings showed that most of the faculty were 30-50 years old, master's degree holders, and has been serving the college for 2-4 years. The three facets of classroom management, namely, time and physical environment, classroom discipline, and routines 
were identified by respondents as needed. Furthermore, there was no significant relationship between the profile and classroom management needs.

In the light of the findings of the study, classroom management needs of the College of Nursing can be addressed through a positive climate of humanism, where a teacher motivates effective learning in students, not through rewards and punishments but through better communication skills, to develop self-regulating behavior.

Recommended citation: Galon, A. L. \& Amparado, M. A. P. (2016). Classroom management needs of the faculty of Nursing. Journal of Research in Nursing, 2(1), 80-89. 